\title{
Prison Inspection and Monitoring: The Need to Reform European Law and Policy
}

\author{
Mary $\operatorname{Rogan}^{1}$ (D) \\ Published online: 10 August 2019 \\ (C) The Author(s) 2019
}

\begin{abstract}
Prison inspection and monitoring bodies are important safeguards against breaches of human rights. In recent years, prison inspection and monitoring has become a key focus for international human rights standards, particularly through the introduction of the Optional Protocol to the Convention against Torture (OPCAT) and the UN's Standard Minimum Rules for the Treatment of Prisoners, which recognize the need for robust and effective systems of prison oversight. This article contends that European legal standards on inspection and monitoring have not kept pace with international developments. The content of European law concerning domestic-level prison inspection and monitoring is not clear, nor has it been consolidated or examined in depth. Through engaging in comparative analysis with international instruments, this article analyses standards promulgated by Council of Europe and European Union bodies on inspection and monitoring, arguing that they need reform in light of international developments. Taking the opportunity presented by the revision process for the European Prison Rules and associated commentary, the article proposes improvements to European legal frameworks. It welcomes proposals for stronger powers for inspection and monitoring bodies, advocates for a specific instrument on prison inspection and monitoring and calls for more empirical understanding of how such bodies operate in practice.
\end{abstract}

Keywords Prisons · European penal policy · European human rights · Inspection and monitoring · European Prison Rules · International human rights law · OPCAT · Mandela Rules

\section{Introduction: Prison Inspection and Monitoring as Ways of Protecting Human Rights}

Prisons pose unique challenges for the promotion of human rights and upholding the rule of law. Far from public view and containing people who often elicit little public sympathy, prisons are places where tensions between the need for security and the simultaneous need to

Mary Rogan

mary.rogan@tcd.ie

1 School of Law, Trinity College Dublin, Dublin 2, Ireland 
ensure human dignity come into sharp relief. Human rights protections are critically important in these environments, where the potential for abuse has been well documented (Carrabine 2004; Simon 2017), the legitimacy of authority can be fragile (Liebling and Arnold 2004; Liebling and Maruna 2005; Tankebe and Liebling 2013) and when prisoners are often drawn from marginalized and vulnerable groups. As Liebling and Crewe (2013: 286) note: 'the prison is a sui generis institution, uniquely liable to abuses and distortion of power'. Prisons are places where public law and human rights principles come under particular strain.

One strategy which seeks to prevent ill-treatment and other breaches of rights in prisons has been to put in place mechanisms to inspect prisons and monitor how human rights obligations are being fulfilled by prison authorities. Such visits, especially as carried out by independent bodies, offer ways to prevent violations of human rights, including the most egregious violations in the form of torture and inhuman or degrading treatment. While there is great variety in the systems established to fulfil this aim, such activity tends to involve giving bodies the task of visiting prisons on a regular basis, reporting on their findings and making recommendations. Prison inspection and monitoring can take place at the national and the supranational or regional level. This article focuses on domestic or national level prison inspection and monitoring.

The principle that the inspection and monitoring of prisons can promote the protection of human rights and, specifically, prevent torture and ill-treatment, has become well established in international human rights law, particularly in the past two decades. This is especially apparent in the adoption of the Optional Protocol to the Convention against Torture (hereafter "OPCAT") and the revision of the UN Standard Minimum Rules (hereafter the "Mandela Rules") in 2015. These two foundational international instruments for the protection of rights in prison have recognized the potential power of regular inspection and monitoring to prevent ill-treatment in places where people are deprived of their liberty and are therefore vulnerable. OCPAT requires state parties to establish National Preventive Mechanisms (hereafter "NPMs"), which have the task of visiting places where people are deprived of their liberty, to help prevent against torture and ill-treatment. OPCAT is based on the premise that the prevention of torture and other forms of cruel, inhuman or degrading treatment or punishment can be supported by means of regular visits by independent bodies to places of detention. The Convention Against Torture (CAT) originally contained no mechanism by which bodies would visit places where people are deprived of their liberty and the process by which OPCAT was drafted was long and challenging (Murray et al. 2011). Thirty-eight Council of Europe Member States have designated NPMs (Hardwick and Murray 2019), while 26 of 28 European Union Member States have done so at the time of writing.

In light of its global reach, OPCAT represents perhaps the highpoint in international human rights law for the prevention of torture by means of monitoring. Subsequent to OPCAT, revised UN SMRs were also concluded in 2015. The Mandela Rules substantially amended the original provisions on prison inspection and monitoring. The original formulation in rule 36 stated that there should be 'regular inspection' of penal institutions by qualified and experienced inspectors. While this was an important statement of principle, as one United Nations document on the new rules puts it, the 1955 formulation was 'vague' (UNODC 2017). OPCAT is said to have 'inspired' the language in the new Mandela Rules (UNODC 2017). The Mandela Rules require states to establish oversight mechanisms for prisons with the aim of protecting human rights, with clear powers to enable them to carry out such visits. The interrelated nature of the provisions on inspection and monitoring in the Mandela Rules and OPCAT was made clear by Sir Nigel Rodley (2015), who made this comment on the then 
draft provisions: 'this remarkable innovation amounts to the effective universalisation of an obligation on State parties to implement the Optional Protocol to the UN Convention against Torture'. These developments are indeed remarkable, involving a near global effort to ensure that prisons are subject to independent inspection and monitoring.

When it comes to the European approach in this field, scholars have increasingly turned their attention to penal policy and human rights standards. Protecting rights in prisons is, in fact, considered to be a strong feature in the European approach to punishment, especially when compared to the more punitive United States (Daems et al. 2014; Snacken 2010; Snacken and Dumortier 2012; van Zyl Smit and Snacken 2009; van Zyl Smit et al. 2014; Morgan and Evans 1994), though the empirical evidence-base for these claims requires further development. European human rights standards contain clear, albeit relatively bare, requirements on states to put in place prison inspection and monitoring bodies. The vast majority of the standards come from the Council of Europe rather than the European Union (EU), though, as will be seen, the EU is likely to become more active in the area of prison conditions in the future. Both sources of standards will be examined in this article.

Rule 9 of the Council of Europe's minimum standards for the treatment of prisoners and the administration of prisons, the European Prison Rules (EPRs), describes the 'basic principle' that 'all prisons shall be subject to regular governmental inspection and independent monitoring'. These rules are currently in the process of revision (European Committee on Crime Problems 2017, 2018a, b, c, d, 2019a, b). The commentary to the rules, which provides supplementary explanation and elaboration of individual rules, has already been revised. That revised commentary strengthens some aspects of the EPRs' approach to inspection and monitoring bodies. The current revision process means that the proposals made here are especially timely. Changes proposed to the rules, considered in this article, will go a long way to improving the human rights standards which Council of Europe member states must comply with in this field. However, as will be discussed, much more action is necessary to ensure that Europe has an optimal set of standards to direct the work of prison inspection and monitoring bodies. As well as a need to strengthen the powers which prison inspection and monitoring bodies have under the EPRs, international developments require that prison inspection and monitoring bodies receive more specific and in-depth attention.

The Council of Europe has a long track record in the area of prison monitoring when viewed in comparative perspective. Long before the long process leading to the eventual adoption of OPCAT concluded, the Council of Europe created a supranational monitoring body to visit places of detention. This body, the European Committee for the Prevention of Torture and Inhuman or Degrading Treatment or Punishment (hereafter "CPT"), has the power to visit places where people are deprived of their liberty in Council of Europe Member States and report to the government on their findings. Usually these findings are made public (Evans and Morgan 1998; Morgan and Evans 1999). In light of this 30 year history and experience of prison monitoring, one would expect that the Council of Europe's institutions would have dedicated more attention to domestic prison inspection and monitoring bodies, and that its legal instruments in this area would be models for others. This article contends, however, that, when it comes to domestic forms of inspection and monitoring, Europe has followed rather than led developments in international human rights law.

Through engaging in a comparative analysis of prison law sources developed by the United Nations and those of the Council of Europe and the European Union, the article examines the ways in which European approaches to inspection and monitoring could be strengthened, making specific recommendations for how European human rights principles in this field 
could be improved. It argues, in particular, that the existing rules are deficient, particularly when it comes to the powers of inspection and monitoring bodies. Proposed changes to these rules will improve this situation. However, the paper argues, ultimately, that a bespoke instrument on prison inspection and monitoring is needed from either the Council of Europe, or the EU, or both.

\section{Prison Inspection and Monitoring: Defining the Terms}

The inspection and monitoring of prisons may fulfil a variety of functions, from auditing and examinations of budgets, to financial and strategic planning, to assessments of the compliance with national and international law governing the treatment of prisoners (Mushlin and Deitch 2010). Part VI of the European Prison Rules refers to the role of prison inspection and monitoring as assessing whether prisons are administered in accordance with law (Rule 92), and the conditions of detention and the treatment of prisoners (Rule 93).

While the establishment of prison inspection and monitoring bodies is a requirement for all Council of Europe Member States, no single model for such bodies exists in Europe. As Vagg notes: 'there might be widely different conceptions of what kinds of prison inspection and monitoring are necessary and why' in different countries (Vagg 1994: 93; see also Dünkel and Morgenstern 2018; Lappi-Seppäla and Koskenniemi 2018; van Zyl Smit 2010). The types of bodies also vary. Some states may utilize offices of Ombudsmen, prosecutors and/or judicial oversight of prisons. Oversight and monitoring may also be undertaken by civil society organizations. In many European countries, prison inspection or oversight bodies are designated as NPMs under OPCAT, with the power to visit places where people are deprived of their liberty (Hardwick and Murray 2019).

Prison authorities or responsible ministries may establish internal forms of inspection, whereby a particular branch or unit of the organization responsible for running prisons has the function of inspecting prisons on a regular basis. As will be seen further below, these bodies can play an important role in ensuring prisons are well-run, but must be complemented by external forms of prison oversight, involving bodies which are independent of the prison authorities visiting and examining prisons.

Although there may be a great deal of variety in the forms which bodies having oversight of human rights in prisons take (Padfield 2018), and, in some circumstances, overlap in their activities, prison inspection and monitoring bodies have a distinctive mission and interest. Their function is also usually different from that performed by judicial investigations and adjudications. Inspection and monitoring bodies usually do not have powers of enforcement, focusing, instead, on general efforts to prevent ill-treatment and human rights violations. As Bicknell and Evans state with reference to NPMs, arguably applicable to many prison inspection and monitoring bodies:

rather than being primarily concerned with compliance, or accountability for breaches of human rights obligations, they are focused on measures that might be taken in order to ensure that ill-treatment does not occur. (Bicknell and Evans 2017: 14)

This focus usually finds expression in conducting regular visits to prisons, reporting on what has been found and making recommendations on how to improve the situation.

Empirical assessment of the activities, impact and value of prison inspection and monitoring in practice is surprising limited, and, as Padfield notes (2018), much more analysis is 
necessary. The belief in prison oversight evident in the discussions behind the introduction of OPCAT and revised Mandela Rules, for example, rests on a surprisingly limited research base. The literature which does exist does not yet give a clear picture of the outcomes of inspection and monitoring. Daems (2016), for example, has found that state responses to CPT visits can vary greatly, from genuine efforts to implement the CPT's recommendations, to stalling tactics, to outright contention and rejection. Crewe (2009) has found a distinct lack of trust in certain monitoring bodies amongst prisoners in a wide-ranging ethnographic study of an English prison. Bicknell and Evans (2017), furthermore, argue that there remains some way to go before it can be said that NPMs operating in Europe have achieved a human rights-focused approach within domestic penal practice. Indeed, there is no clear way for researchers or practitioners to access all NPM reports, with no single repository in which to find them or comparable reporting standards by which to judge them. Other work has found (van der Valk and Rogan, forthcoming, reference omitted) that prisoners have conflicting views of prison oversight, viewing it as useful in principle, but showing deep scepticism about its ability to improve their lives. We know almost nothing about the resources which prison oversight bodies have or need, about how those who work for such organizations experience interactions with staff (though for an honourable exception see Bennett (2016)), with prison authorities and with prisoners. We do not yet have extensive research on the extent to which those bodies get to see the true picture in prisons, especially in the context of shorter visits.

It is surprising and disappointing that an area of such potential importance to the promotion of human rights in closed settings has been so under-researched. Although we cannot conclude that prison oversight fulfils its objectives in all settings, the principle that some kind of independent assessment of what is happening in prisons has become a key feature of international human rights law on the deprivation of liberty, including in Europe.

\section{What Does European Law Require Concerning Prison Inspection and Monitoring?}

\section{The Council of Europe and Inspection and Monitoring}

Neither the Council of Europe nor the European Union has a specific instrument governing domestic-level prison inspection and monitoring bodies. The governing legal principles, therefore, must be garnered from a mixture of sources, some of which do not have the status of legally binding instruments but which influence, for example, the position of the European Court of Human Rights (hereafter "ECtHR"). In this section of the article, the European legal sources (from both the Council of Europe and EU) applicable in the area of prison inspection and monitoring will be examined.

As noted above, domestic-level prison inspection and monitoring is a requirement of the European Prison Rules, a Council of Europe instrument. The present rules date from 2006. The commentary to the rules was revised in 2018 (European Committee on Crime Problems 2018a), with the redrafting process led by Dr. Harvey Slade and Professor Dirk van Zyl Smit. The rules are currently under revision by the Council of Europe's Council for Penological Cooperation, with key input from the same two experts. This group will make recommendations to the Committee on Crime Problems, which is the ultimate arbiter of what the rules should contain. The content of the 2006 rules and commentary is discussed in this section of the paper, with the proposed revisions analyzed later. 
The 2006 rules contain relatively scant guidance on what precisely domestic prison inspection and monitoring bodies should do. Instead, they set out in broad terms what principles which should apply to prison inspection and monitoring bodies. Only three provisions, outside of the statement of basic principles, apply to prison inspection and monitoring at present. These are contained in Part VI of the European Prison Rules. Rule 92 requires regular inspections of prisons by governmental agencies for the purpose of assessing 'whether they are administered in accordance with the requirements of national and international law, and the provisions of these rules'. Rule 93 states:

1. The conditions of detention and the treatment of prisoners shall be monitored by an independent body or bodies whose findings shall be made public.

2. Such independent monitoring body or bodies shall be encouraged to co-operate with those international agencies that are legally entitled to visit prisons.

The distinction made between governmental inspection and independent monitoring is notable, and it is reiterated in the 2018 commentary. The commentary recognizes that governmental inspection may take on the role of examining budgetary matters and the efficiency of the operation of prisons. However, the commentary also states that such inspection 'should not focus narrowly on technical administrative matters ... its wider obligation is to take into account international law and these rules' (European Committee on Crime Problems 2018a: 65). The commentary further requires such agencies or bodies to be established by, and report to, the highest possible authorities (European Committee on Crime Problems 2018a: 95).

It is also notable that the provisions on independent monitoring in the 2006 rules are rather minimal. The revised commentary supplements what is essentially a bare requirement in the 2006 European Prison Rules to have an independent prison monitoring body in each member state, having a focus on conditions of detention and the treatment of prisoners and making public findings. While the importance of such an obligation should not be understated, the provisions on independent monitoring are certainly not fulsome. This is a matter which is scheduled for reform and will be returned to below when comparing European standards to those of other sources.

\section{The CPT and Domestic Prison Inspection and Monitoring}

While the 2006 European Prison Rules contain very little by way of specific or detailed guidance for states on how precisely to organize their prison inspection and monitoring activities, the CPT has made efforts to provide detailed information to domestic prison inspection bodies on how they should operate. The CPT's own operations involve supranational monitoring of prisons by means of visits to Council of Europe member states, usually about every four to five years, but the CPT has also emphasized the need for domestic inspection and monitoring, stating that: 'effective grievance and inspection procedures are fundamental safeguards against ill-treatment in prisons' (CPT 1992: 3). This is all the more important given the inherently limited perspective which can be gained from a visit to a country of perhaps a week in duration once every few years, which is the general approach of the CPT unless the circumstances call for more frequent visits.

The CPT now regularly reports on its relationship with a country's NPM or other prison oversight body in its individualized country reports (Bicknell and Evans 2017: 23; see, for example, CPT 2017a, CPT 2017b; CPT, 2018). The CPT has not created a set of standards for 
prison inspection specifically, however, a review of country reports since 2007 (presented below) shows that there are some recurring concerns for the CPT regarding domestic inspection and monitoring arrangements, as well as areas which the CPT considers to be good practice. These comments do not have force of law, and no enforcement proceedings can be taken by the CPT against countries which do not comply with their suggestions. These recommendations and principles have also never been consolidated or published by the CPT as specific guidance for domestic prison inspection and monitoring bodies. This is a missed opportunity. While the CPT's influence has yet to be systematically studied, its experience in prison monitoring does lend value to its views of how domestic monitoring can take place. A document containing the CPT's guidance would be a useful tool, particularly for more recently established bodies.

The CPT has stated regularly that inspection and monitoring bodies should be able to meet with prisoners and receive correspondence from them confidentially (CPT 2015a; CPT 2017a; CPT, 2018; CPT 2016a). Inspection and monitoring bodies should contact prisoners and prison staff directly and not just meet those who have requested to talk to them (CPT 2015a; CPT 2017a; CPT 2015b). Inspection and monitoring bodies must make themselves visible within the prison; the post-facto examination of documentation is not sufficient to fulfil their role (CPT 2015a; CPT 2017b; CPT 2010a, 2010b). Frequent announced and unannounced visits are required (CPT 2016b; CPT, 2018). Inspectors and monitors must also be able to enter all areas of a prison and walk around freely (CPT 2016b; CPT, 2018; CPT 2017c; CPT 2015c). The CPT has criticized reports from inspectors that are succinct with no information on how the conclusions drawn were arrived at (CPT 2015c).

In the view of the $\mathrm{CPT}$, inspection and monitoring bodies should receive the resources they need to do their work effectively (CPT 2015d; CPT 2015e; CPT 2014a), as well as their own staff, if the body in question has broader remit than solely the inspection of prisons (CPT 2014b). Inspectors also need to be provided with the necessary expertise for them to do their work, e.g. through having experts working on inspection teams or acting as consultant to them, especially in the area of healthcare (CPT 2015d).

The CPT has expressed concern about reprisals against those who speak to inspectors and monitors (CPT 2010a, 2010b), strongly stating the view that adequate steps must be taken in order to prevent such actions. The prison authorities must also ensure that detainees must be provided with information, in a language they understand, on complaints and monitoring mechanisms in order for them to be effective (CPT 2014c).

The CPT's reports on particular countries gives detailed guidance to prison inspection and monitoring bodies on how to conduct their activities. The originating Convention that established the CPT also gives an indication of European standards in this area. The CPT was established by means of the European Convention for the Prevention of Torture and Inhuman or Degrading Treatment or Punishment Convention (ETS No. 126), which entered into force in 1989. That Convention provided certain powers to the CPT when visiting states. Unrestricted access to all places of detention and those in detention, as well as confidentiality of communications to the CPT are very strong features of that Convention. ${ }^{1}$ States parties are required to provide access to their territories and the right to travel without restriction, along with full information on places people deprived of their liberty are being held, unlimited access to such places and the right to move within them without restriction (Article 8 (2)). Private

\footnotetext{
${ }^{1}$ It can also be seen in paragraph 63 of the Explanatory Report to the European Convention for the Prevention of Torture and Inhuman or Degrading Treatment or Punishment, ETS 126, Strasbourg, November 261987.
} 
interviews with detainees are also to be permitted by the state (Article 8 (3)). The power to make recommendations to the authorities is also provided to the CPT (Article 10(1)), though it remains within the power of the State to decide whether the report is to be made public (Article 11(2)). The explanatory report to the Convention emphasizes that its role is to prevent illtreatment, not to condemn States or to hold them to account in the same way that a judicial body would do. ${ }^{2}$

It is clear from these sources, then, that Council of Europe states ought to establish independent agencies to monitor the treatment of people in prison and the conditions of detention therein. As will be seen in the next section of this article, the European Court of Human Rights has not made the establishment of such bodies an enforceable legal obligation for Council of Europe member states, nor has the Court proven to be a source of guidance for states on how such inspection and monitoring bodies should operate.

\section{The European Court of Human Rights and Inspection and Monitoring}

The ECtHR relies on the reports of domestic and international prison inspection and monitoring bodies to garner information as to what prison conditions are like in a particular state (van Zyl Smit and Snacken 2009, p 9). These reports are used, for example, in assessments of whether Article 3 of the European Convention on Human Rights (hereafter "the Convention") has been breached by reason of poor conditions in prisons. There are numerous examples of the Court citing CPT reports concerning the situation in a state's prisons, or as a guide for interpreting Convention principles (for example, Ananyev v. Russia (Application nos. 42525/ 07 and 60800/08, 10 January 2012); Vasilescu v. Belgium (Application no. 64682/12, 25 November 2014); Torreggiani v. Italy (Grand Chamber, Application no. 4317/08, 8 January 2013)). The Court has also referred to domestic bodies in their assessment of prison conditions (See, for example, Bigović v. Montenegro Application no. 48343/16, March 19 2019; Zabelos and Others v. Greece Application no. 1167/15, May 17 2018; Danilczuk v. Cyprus Application no. 21318/12, April 32018 where the Court drew on reports of the Ombudsman). In Muršić v. Croatia (Grand Chamber, Application no. 7334/13, 20 October 2016), the Court was influenced in its assessment of minimum permissible space for prisoners by the CPT's approach to such calculations. The Court described itself as being 'attentive' (para. 113) to the CPT's standards.

van Zyl Smit and Snacken argue that the Court's stronger approach towards the protection of people in prison against violations of their human rights is 'testimony to the increased influence of the CPT' (van Zyl Smit and Snacken 2009, p 9). However, the Court has also made clear that it is not itself a kind of prison monitor akin to the CPT, which it describes as 'conceptually different' (para. 113), a characterization the CPT agrees with. The Court has made clear that the standards set by the CPT are not necessarily those applicable to determine that the Convention has been breached, which essentially means that the Convention standards might not be as high as those applied by the CPT.

The ECtHR's main encounters with prison inspection and monitoring bodies have therefore been when using their reports as information sources and, at times with the CPT, when

\footnotetext{
${ }^{2}$ Para 20 of the Explanatory Report to the European Convention for the Prevention of Torture and Inhuman or Degrading Treatment or Punishment, ETS 126, Strasbourg, November 261987 states: 'the purpose of the committee is not to condemn States but, in a spirit of co-operation and through advice, to seek improvements, if necessary, in the protection of persons deprived of their liberty'.
} 
examining its standards in order to apply Convention principles. This is a rather limited approach. The Court has never stated that the Convention requires states to establish prison inspection and monitoring mechanisms of a certain structure or form. The Court has, moreover, not been a key source of guidance to states on how to regulate their inspection and monitoring mechanisms. The closest the Court has come to examining what kinds of powers prison inspection and monitoring bodies must have has been when it is called to assess whether effective remedies exist for prisoners in a state.

Article 13 of the Convention establishes the right to an effective remedy. Under Article 13, two types of remedies must be available: a preventive remedy; and a compensatory remedy. A preventive remedy in this context is one which can bring conditions that amount to inhuman and degrading treatment to an end rapidly (e.g. through an order of a court), while a compensatory remedy provides for some kind of recompense for the breach of rights. In cases where prisoners are, for example, alleging a breach of Article 3 (the prohibition on torture and inhuman and degrading treatment), there is often a dispute as to whether the prisoner at issue has access to or has utilized an effective remedy by which the alleged violation of the Convention could be examined and addressed. Such remedies might take the form of, for example, bringing a complaint to a relevant body, or taking the matter to court. Prison inspection and monitoring bodies sometimes come in for analysis in these kinds of cases as they may have some remedies at their disposal, usually as part of other work (e.g. complaints resolution) that the body undertakes.

The ECtHR has determined that preventive remedies must fulfil certain minimum criteria in order to be considered effective, in the context of claims of violations of Article 3 in prisons. $^{3}$ Most importantly, in this context, a prisoner with a complaint under the Convention must be able to access a mechanism with the above characteristics in order to be considered as having access to an effective remedy. Under Article 13, if a body cannot provide a binding decision in the case of a prisoner who has been subject to a violation of the Convention, then the remedy will not be considered effective. Inspection and monitoring bodies usually do not have these powers. This is a key reason why the ECtHR has tended to overlook prison inspection and monitoring bodies when assessing compliance with Article 13. Bodies designed to prevent illtreatment and human rights violations, by means of visits, creating dialogue with the relevant authorities and making recommendations, as opposed to judicial bodies with enforceable powers, cannot be considered effective remedies under Article 13. In Ananyev v Russia (2012) for example, the Court was very clear in its view that the Ombudsman with responsibility for prisons could not constitute an effective remedy under Article 13. The Court stated:

Their task is different: they identify various human rights issues on the basis of individual complaints and other information at their disposal, highlight problems in their annual reports and work out solutions in co-operation with regional and federal authorities (internal citations omitted). While their activities may usefully contribute to general improvement of conditions of detention, the ombudsmen remain unable, in view

\footnotetext{
${ }^{3}$ For example, see: Silver and others $v$ United Kingdom, Nos. 5947/72, 6205/73, 7052/75, 7107/75, 7113/75 and 7136/75, Merits and Just Satisfaction, 25 March 193; Rodić and others v Bosnia Herzegovina, No. 22893/05, Merits and Just Satisfaction, 27 May 2008; Neshkov v Bulgaria Nos. 36925/10, 21487/12, 73196/12, 77718/12, 9717/13, Merits and Just Satisfaction, 27 January 2015; Varga v Hungary Nos. 14097/12, 43135/12, 73712/12, 34001/13,44055/13 and 64586/13, Merits and Just Satisfaction, 10 March 2015; Ananyev and others v Russia, Nos. 42525/07 and 60800/08, Pilot Judgment, 10 April 2012; Torreggiani et autres c Italie, No. 43517/09, 46882/09, 55400/09 et al., Merits and Just Satisfaction, 27 May 2013; Stella v Italy, Nos. 49169/09, 54908/09, 55156/09 et al., Merits and Just Satisfaction, 16 September 2014.
} 
of their specific remit, to provide redress in individual cases as required by the

Convention (para. 106)

This conclusion is the logical and understandable outcome of the Court's position that, to constitute an effective remedy, a body must be able to provide individual redress. The effect of this, however, has been that the ECtHR has been unable to provide guidance to states on how to organize their prison inspection and monitoring systems. The Court is therefore unlikely to be a key source of criteria which prison inspection and monitoring bodies in Council of Europe countries must meet, other sources of guidance will be required.

The Council of Europe's Committee of Ministers, which examines states' implementation of ECtHR's judgments has shown some interest in prison inspection and monitoring bodies as ways for states to demonstrate their compliance with the Convention. The Committee of Ministers is tasked with supervising the execution of the court's judgments and receives regular reports from the defendant state in the case, along with submissions from NGOs and other interested parties on the steps taken to implement the court's decisions. The positions adopted by the Committee of Ministers suggest that that inspection and monitoring bodies provide comfort to the Committee that Convention rights are being protected, even if those bodies are not formally required under the Convention. For example, in the course of the Committee's monitoring of the execution of the Torreggiani v. Italy (2013) decision, which found that overcrowding and poor conditions in the Italian prison system breached Article 3, the Italian government put forward the establishment of an NPM as a form of prevention of human rights violations (Committee of Ministers 2014, 2015). The Committee of Ministers, in deciding to end the supervision process, emphasized that the state had put in place general measures seeking to prevent violations of the Convention, without distinguishing between particular reforms to the judicial oversight of prisons and the creation of the NPM (Favuzza 2017). The presence of an NPM has also been mentioned by the Hungarian government as an example of a means by which a prisoner may complain about his/her detention. (Committee of Ministers 2019: 40). The Russian authorities in the assessment of the Ananyev decision also referred to a series of prison oversight mechanisms in its account of the steps it had taken to improve conditions of detention. The government referred to the inspection of prisons by the Commissioners for Human Rights of the Russian Federation and the creation of the Public Monitoring Commissions, which provide recommendations to the prison authorities. The Committee of Ministers noted 'with interest the reinforcement of inspection and review mechanisms to ensure that detention conditions comply with Convention requirements' (Committee of Ministers 2017).

Both the Court and the Committee of Ministers, therefore, see a role for inspectors and monitors in the general prevention of torture and ill-treatment, but not as bodies capable of giving effective remedies to prisoners under the Convention. Though no explicit Convention requirement to have inspection and monitoring bodies presently exists, state responses in the Committee of Ministers' proceedings imply that prison oversight bodies are a means by which to demonstrate compliance with the Convention.

As this analysis has shown, apart from the EPRs and the work of the CPT, there is limited and relatively weak guidance from Council of Europe bodies concerning how prison inspection and monitoring mechanisms should operate or be governed. Outside of the EPRs, the Council of Europe has not yet created recommendations or other instruments concerning prison oversight. This is a significant deficiency in the Council of Europe's frameworks for protecting rights in prisons and should be remedied. 


\section{The European Union and Prison Inspection and Monitoring}

Although historically less active in the area of prisons than the Council of Europe, in recent years the European Union (hereafter "EU") has become more interested in, and critical of, prison conditions in Member States (European Parliament Resolution 2011, 2014; European Council 2010). The European Parliament has stated emphatically that Member States should implement 'effective and independent national supervision mechanisms for prison and detention centres' (European Parliament Resolution 2011: para 19), though, as yet, as is the case with the Council of Europe, no specific EU legal instruments exist concerning prison inspection and monitoring bodies. A seminal decision of the ECJ, however, suggests the EU is likely to become a driver in the establishment of minimum standards to guide inspection and monitoring bodies' activity. The case of Aranyosi and Căldăraru (2016) concerned the circumstances in which a judicial authority in an EU Member State could refuse to execute a European Arrest Warrant (hereafter "EAW"), when there is evidence that the conditions of detention in the requesting Member State breach fundamental rights. The judicial authority may postpone the execution of the warrant should such concerns exist. The ECJ held that, in such cases, the executing judicial authority must seek information from the requesting Member State on the conditions in which the person will be detained. The ECJ referred to reports of the CPT and decisions of the ECtHR as sources of such information. An executing judicial authority must then seek information on the precise conditions of detention that the person is likely to be held in, following the execution of the EAW. The ECJ held that the executing judicial authority may also include a request for information from the issuing Member State on:

any national or international procedures and mechanisms for monitoring detention conditions, linked, for example, to visits to prisons, which make it possible to assess the current state of detention conditions in those prisons (2016: para 96).

The implications of this decision are that Member States will be likely to be called upon to provide information about their inspection and monitoring bodies, and how they operate. Further implications of the decision are that reports of inspection and monitoring bodies are likely to become of central importance in decisions as to whether or not an EAW should be executed in circumstances where there are concerns that the conditions of detention breach fundamental rights. The test contained in the decision has subsequently been approved in Minister for Justice and Equality v. LM (Case C-216/18 PPU, Minister for Justice and Equality v LM, ECLI:EU:C:2018:586).

The likely medium-term effects of this decision will be to require EU Member States to ensure that they have bodies which can provide information on the status of human rights protections in prisons. It remains to be seen if the ECJ will ultimately pass judgment on whether particular kinds of inspection and monitoring bodies are adequate for the purpose outlined in this decision. Common standards for how inspection and monitoring bodies operate and report on their findings may be needed for 'the sharing of information' as part of the EAW procedure outlined by the ECJ. At a minimum, countries without inspection and monitoring bodies may find themselves being unable to provide the necessary information for the execution of EAWs. All of this suggests that the EU is likely to turn its attention to prison inspection and monitoring bodies as ways to shore up the systems for cooperation in the Area of Freedom, Security and Justice. At present, however, the EU has no specific standards concerning the regulation of prison inspection and monitoring. 


\section{The European Legal Framework for Prison Inspection and Monitoring in Comparative Perspective: The Need for Reform}

The European Prison Rules, as we have seen, are the primary instrument governing prison inspection and monitoring at the pan-European level, and the only European document with any legal standing on this subject. Since the rules were published in 2006, two important instruments have been passed: revised United Nations' Mandela Rules and OPCAT. These two instruments have surpassed the provisions of the European Prison Rules in important respects. In this section of the article, these new standards will be examined, and their potential import for European instruments will be assessed.

The Mandela Rules substantially amended and strengthened the provisions of the previous UN Standard Minimum Rules concerning the inspection and monitoring of prisons and were influenced by OPCAT. OPCAT established the UN's Subcommittee on Prevention of Torture and other Cruel, Inhuman or Degrading Treatment or Punishment (hereafter "SPT"), which has the power to visit places of detention within states party to the Convention (Murray et al. 2011), as well as domestic-level NPMs. These entities have the remit and powers to visit places of detention in order to prevent torture and other inhuman or degrading treatment or punishment. The European Parliament has called on Member States and accession countries to sign and ratify OPCAT and also has encouraged the EU itself to sign and ratify OPCAT, as part of its policy vis-à-vis third countries. ${ }^{4}$ Notably, however, within the EU, two states have yet to designate NPMs: Ireland and Slovakia.

While the influence of European approaches to inspection and monitoring, particularly through the activity of the CPT, is visible in the development of OPCAT and the Mandela Rules (Bicknell and Evans 2017), Europe has been behind the curve in this area, and it is only since 2018 that we see efforts by the Council of Europe to regulate its domestic inspection and monitoring bodies in the same way that the United Nations has, through OPCAT and the Mandela Rules.

\section{Revising the European Prison Rules in Light of International Developments}

The European Prison Rules are currently under revision and this process offers a very useful opportunity to strengthen European protections for human rights in prisons through the development of oversight bodies. The revision process for the rules commenced in 2017. As an instrument applicable in 47 Council of Europe Member States, this revision process could have a wide-ranging and profound impact on domestic prison inspection and monitoring bodies. In this section of the article, those proposed revisions are examined and specific reforms to the European Prison Rules are advocated.

The first and most urgently needed revision to the existing rules concerns the powers of prison inspection and monitoring bodies. The 2006 rules state simply that the findings of independent monitoring bodies "shall be made public" (in rule 93.1), but no other powers are described. The revised commentary of 2018 sought to address this notable gap by including a more detailed set of powers that inspection bodies should have. The revised commentary now states that monitoring bodies should have

\footnotetext{
4 "European Parliament Resolution of 15 December 2011 on detention conditions in the EU (2011/2897(RSP))" paragraph 19.
} 
wide authority to access information, choose freely which prisons to visit, conduct private and fully confidential interviews with prisoners and prison staff and make recommendations on what needs to be done to meet standards set by national and international law (European Committee on Crime Problems 2018a: 66). Following the conclusion of the process for revising the commentary, the rules themselves were slated for revision. This revision process has gone through sevearl iterations.

The originally proposed revision to the European Prison Rules included a list of powers that should be guaranteed to independent monitoring bodies (European Committee on Crime Problems 2018b). The powers proposed in the first 2018 formulation were:

(a) Access to prisons and to all prison records, including those relating to requests and complaints, that they require to carry out their monitoring activities; and

(b) Permission to conduct private and fully confidential interviews with prisoners and prison staff.

The powers contained in the proposed revisions were a considerable improvement on those in the current formulation of the EPRs. However, they were rather limited. The reference to access to prisons and all records that bodies require to carry out monitoring activities was a broad formulation and risked the possibility of arguments and doubt about the types of access and records that could be sought.

It is therefore welcome that more recent revisions in 2018, which have been carried over into the 2019 revisions (Committee on Crime Problems 2018c, d, 2019a, b) makes the powers of inspection and monitoring bodies much clearer and stronger. The proposed formulation is as follows:

93.2 Such independent monitoring bodies shall be guaranteed:

a. access to all prisons and parts of prisons, and to prison records, including those relating to requests and complaints, that they require to carry out their monitoring activities;

b. choice of which prisons to visit, including by making unannounced visits at their own initiative and which prisoners to interview; and

c. permission to conduct private and fully confidential interviews with prisoners and prison staff. ${ }^{5}$

The 2019 version of the revisions bring the EPRs largely into line with the Mandela Rules and OPCAT and the additional detail is valuable. The Mandela Rules contain a detailed set of powers that both internal and external forms of inspection bodies should hold. Under rule 84, prison inspectors are given the authority:

(a) To access all information on the numbers of prisoners and places and locations of detention, as well as all information relevant to the treatment of prisoners, including their records and conditions of detention;

(b) To freely choose which prisons to visit, including by making unannounced visits at their own initiative, and which prisoners to interview;

\footnotetext{
5 Two revisions to the European Prison Rules were made in 2019, one on February 42019 and the other on March 24 2019. These revisions are largely comparable in the area of prison inspection and monitoring, with one notable addition of 'at their own initiative' after 'by making unannounced visits' in rule 93.2.b.
} 
(c) To conduct private and fully confidential interviews with prisoners and prison staff in the course of their visits;

(d) To make recommendations to the prison administration and other competent authorities.

It is notable that the commentary to the EPRs now cross-references this Mandela rule describing it as 'further' spelling out the scope of this EPR. This indicates the influence the Mandela Rules have had on the drafting process.

The 2019 revisions also bring the EPRs closer to OPCAT. Article 19 of OPCAT states that NPMs must be granted, at a minimum, the power to regularly examine the treatment of people deprived of their liberty (19(a)), and, to do so, under Article 20, state parties must grant them access to all information concerning the following: the number of people in prison in the particular state; the number of prisons in the particular state and their locations; access to all information referring to the treatment of prisoners, as well as the conditions of detention; access to all places of detention; the opportunity to have private interviews; the liberty to choose where to conduct visits and with whom to speak.

The proposed revision to the EPRs does not refer to information on the numbers and locations of prisons in Member States, which could be included in a revised rule. The proposed revision to the EPRs does, however, include reference to inspection and monitoring bodies obtaining information on requests and complaints made by prisoners. This specific reference to requests and complaints is not found in the Mandela Rules or OPCAT. This inclusion is welcome as complaints and requests can be important sources of information about concerns happening in prison and issues which may not be brought to the attention of the body during a particular visit or inspection.

The reference in the proposed revision to 'permission' to conduct private and fully confidential interviews, however, sets the wrong tone. Permission suggests a power differential between the oversight body and the prison; facilitation would be a more appropriate concept. The Mandela Rules' term of 'authority' and OPCAT's reference to 'liberty' in this respect are preferable.

A particular omission in the 2006 European Prison Rules concerned the power to make recommendations on the part of prison inspection and monitoring bodies. An early proposed revision to the European Prison Rules sought to address this deficiency by stating that when an independent monitoring body finds that the detention of prisoners is not in accordance with the standards of national and international law, it 'may' make recommendations on what needs to be done to meet those standards (European Committee on Crime Problems 2018b). This has been strengthened in the more recent formulation, which states that monitoring bodies shall have 'the authority' (rule 93.4) to make recommendations to the prison administration and other competent bodies (European Committee on Crime Problems 2019b). This revision is necessary to ensure that the EPRs are in line with other standards. For example, Article 19 of OPCAT gives NPMs the powers to make recommendations to the relevant authorities, a power which is also contained in the Mandela Rules (rule 84(d)). The power to make recommendations is at the heart of the preventive mandate of prison inspection and monitoring bodies. Recommendations allow inspection and monitoring bodies to engage in a dialogue with state authorities, and support the development of better prison practices. This stronger statement in the EPRs is valuable.

The response of the authorities is now dealt with in the 2019 revisions, a matter on which the 2006 rules were silent. The Mandela Rules require the prison authorities to indicate within 
a reasonable time frame whether or not they will implement the recommendations (Rule 85 (2)). This requirement is not in the current European Prison Rules, but has been proposed in the 2019 revisions, which state:

93.5 The national authorities or prison administration shall inform these bodies, within a reasonable time, on the action being taken in respect of such recommendations (European Committee on Crime Problems 2019b).

Such an inclusion will be a valuable development to ensure greater public accountability for prison authorities' responses to the findings of bodies charged with the protection of human rights. It would further allow monitoring bodies to assess the response of the prison authorities and their attitude towards dialogue and cooperation.

Another area which merits attention concerns the ability of a prison inspection and monitoring body to publish its reports. The 2006 iteration of the European Prison Rules contained a statement that the reports of independent monitors shall be made public. This is a more forceful requirement than that contained in the Mandela Rules, although such an imperative was in an earlier draft of those rules. The 2019 revised rules seek to retain this requirement, which is to be welcomed. The publication of reports is an essential feature of the information sharing role inspection and monitoring bodies ought to have with the general public, about places which are far from public view. The 2019 revision goes further than this already strong requirement, stating that not only monitoring reports but also 'the responses thereto' (rule 93.6) shall be made public. This is a striking development, particularly as practices of prison authorities and monitoring bodies concerning the publication of responses vary widely across Europe. This particular revision will likely require the greatest change on the part of prison authorities. It is a very welcome one, allowing the public to see what action, if any, has been taken in response to a monitoring report and if none is taken, what reasons there might be for that position. While this alone will not lead to greater enforcement of recommendations, documentation of responses will at least permit greater oversight by civil society organizations and researchers. As the commentary to the rules puts it: 'without this requirement, recommendations could simply be ignored' (p. 70).

Overall, the proposed rules are a welcome change in light of the very scarce guidance on the powers of inspection and monitoring bodies in the current EPRs, which presently have a sole requirement (though very important) to publish reports. Including a fuller statement of the powers of inspectors and monitors would not only bring the EPRs into line with OPCAT and the Mandela Rules, it would also reflect the position of the CPT concerning the importance of full and unfettered access to prisons and prisoners. Other provisions also merit inclusion.

As well as providing for a power to make recommendations, there should be a power described in the EPRs for prison inspection and monitoring bodies to comment on draft legislation within their area of work. This power is contained in OPCAT (Article 19 (c)). At present, the European Prison Rules do not contain a statement that inspection and monitoring bodies should be able to comment on draft legislation, nor is this proposed for inclusion in the revision process. It is, however, contained in the commentary to the rules (p.69). A power to comment on draft legislation should be included in the rules themselves to reflect the role which such bodies can play in shaping legislation.

A further absence in the current European Prison Rules concerns a matter of considerable concern to the CPT. As discussed above, the CPT has described worrying instances of reprisals against people who have spoken to the CPT. OPCAT contains a requirement that 'no authority or official shall order, apply, permit or tolerate any sanction against any person or organization 
for having communicated to the national preventive mechanism any information, whether true or false, and no such person or organization shall be otherwise prejudiced in any way' (article 21 (1)). A similar statement should be placed in the European Prison Rules. While the commentary states that a person in contact with a monitoring body, and particularly a prisoner, should be protected against any form of sanctions or reprisals, regrettably, the proposed revision contains no such requirement. Including such a statement would send a stronger message to authorities.

\section{Expanding on the European Prison Rules: The Need for a New Instrument on Prison Inspection and Monitoring}

The reforms to the EPRs described above, while welcome, are generally minimum requirements to bring those rules into line with international developments concerning prison inspection and monitoring. Any revised rules cannot, of course, cover every aspect of inspection and monitoring. It is therefore time for the Council of Europe to introduce a standalone instrument, perhaps taking the form of a recommendation or guidelines, on the inspection and monitoring of prisons. Such a document could consolidate the principles elucidated by the CPT in its reports as described above, draw on the experiences of the SPT and NPMs and give more in-depth and specific guidance to states and to inspection and monitoring bodies on how such activity should be conducted. This would be especially useful for those states that are seeking to develop or reshape their inspection and monitoring mechanisms, an activity which is being funded by the EU and Council of Europe in the Balkans, for example. ${ }^{6}$ These guidelines should include a requirement that domestic inspectors and monitors seek to meet directly with all prisoners, not just those who request to see them, and that all correspondence and meetings with prisoners are confidential. These new guidelines should emphasize the importance of inspectors and monitors making themselves visible in the prison, and to ensure there are frequent announced and unannounced visits. More specific guidance on what constitutes independence, e.g. the appointment process for inspection body members, the ability to propose and manage one's own budget, etc., could also be provided. This instrument should also require states to provide prisoners with information, in a language they understand, on the inspection and monitoring mechanisms in place so that prisoners know how to access them if they need to. Awareness-raising campaigns on the work of inspection bodies should also, however, be undertaken with staff, policymakers and with the public.

Given the greater activity of the Council of Europe as compared to the EU in the area of human rights in prisons, it seems intuitive that it would be the most likely source of a European-wide instrument on prison oversight. Such a document would be a natural extension of the European Prison Rules, akin to previous recommendations made by the Council of Europe on, for example, foreign nationals in prisons, or overcrowding. ${ }^{7}$ However, we should not rule out the possibility of the EU acting first and producing guidance on minimum standards for prison inspection and monitoring

\footnotetext{
${ }^{6}$ The EU/Council of Europe Horizontal Facility for the Western Balkans and Turkey (Horizontal Facility) is a cooperation initiative of the European Union and Council of Europe for South East Europe.

${ }^{7}$ For examples of Council of Europe Conventions and Recommendations, please see: https://www.coe. $\mathrm{int} / \mathrm{en} / \mathrm{web} /$ prison/conventions-recommendations
} 
bodies. The implications of the ECJ's decision in Aranyosi and Căldăraru (2016) for the EAW system will place more pressure on Member States to provide evidence of their prison conditions when there is a question mark over their compliance of upholding fundamental rights. That evidence is likely to be most reassuring to executing judicial authorities when it comes from well-resourced, independent inspection and monitoring bodies, with the necessary powers to be able to provide a clear and accurate picture of what is happening in prisons. In the longer term, a set of minimum standards for such bodies may emerge.

\section{Other Future Developments}

It is both likely and necessary that we will see dedicated legal instruments at the panEuropean level for prison inspection and monitoring. It is submitted that, within the Council of Europe at least, increased guidance on inspection and monitoring would be most beneficial through the legislative route rather than through the actions of the ECtHR. First, the requirements of Article 13, as interpreted by the ECtHR, imply that inspection and monitoring bodies will not constitute bodies capable of giving an 'effective remedy' to prisoners, in order to prevent breaches of Article 3. Inspection and monitoring bodies in many countries do not have powers of enforcement and cannot force prison authorities to carry out their recommendations. As such, the ECtHR is inevitably constrained in its ability to regulate such bodies. The legislative avenue has an advantage over using the judicial route, as the latter involves the risk of the European Court of Human Rights being accused of overstepping its remit in the sensitive area of domestic policy on crime and punishment.

The ECtHR, could, however, do more to encourage states to ensure they have excellent mechanisms to prevent ill-treatment in prison. A powerful way to do this would be for the court to factor into its assessment of breaches of Article 3 whether or not there are effective inspection and monitoring systems in place in the state. In this respect, it will be interesting to see if the ECJ will in fact go further than the ECtHR and extend the position in Aranyosi and Căldăraru (2016) towards considering oversight bodies as a factor in deciding if prison conditions are in breach of fundamental rights. Were the decision to result in inspection and monitoring mechanisms becoming relevant to considerations of 'mutual trust' between states, this would have very significant implications, creating a need for minimum standards in how inspection and monitoring bodies operate. It will be illuminating to see how the decision in Aranyosi and Căldăraru (2016) and its subsequent interpretation (Anagnostaras 2016; Xanthopoulou 2018; Glas and Krommendijk 2017) interacts with the ECtHR's positions on inspection and monitoring. As such, the decision of the ECJ may prompt more examination of the role of inspection and monitoring bodies as factors to assess in the prevention of breaches of rights on the part of the ECtHR.

It is also notable that the current legal standards on inspection and monitoring within Europe are resting on a surprisingly limited empirical base (Padfield 2018). Empirical assessment of how members of inspection and monitoring bodies experience their work is needed. Their experiences of the responses of the authorities and negotiating an environment where they seek to prevent ill-treatment in the absence of their findings having any enforceable powers is also necessary (Lappi-Seppäla and Koskenniemi 2018; Dünkel and Morgenstern 2018; Daems and Robert 2017). Such assessment will 
ensure that the legal frameworks guiding the work of members of inspection and monitoring bodies can be based on their lived experiences and best practices. It will also be essential to provide empirical assessment of the operation of the new European Prison Rules when they come into force. More broadly, it is noteworthy that we still lack a clear picture of what prison oversight bodies exist in Europe and the most common structures or mandates for them. We need to understand what forms of oversight perform the task of preventing ill-treatment and other violations of human rights most effectively. More empirical evaluation is required to understand our systems and the effects of inspection and monitoring.

\section{A New Way for Prison Inspection and Monitoring in Europe}

Inspection and monitoring of places where people are deprived of their liberty has become a matter of increasing interest and activity within international human rights discourse. Europe already has a well-established position as an early adopter in the supranational monitoring of prisons through the work of the CPT. The time is now ripe for Europe to ensure its legal instruments for domestic prison oversight bodies reflect the latest thinking. Revisions to the commentary to the European Prison Rules have brought Europe closer to the international human rights standards in this field. The 2019 revisions provide for much stronger powers and obligations, most notably concerning the requirement to publish the responses of the authorities' to monitoring reports. The opportunity presented by the proposed revisions to the rules themselves at present should be grasped to ensure that, at the least, European standards are in line with those promulgated by the United Nations. European bodies should, however, go further and build on these developments by developing a standalone instrument on inspection and monitoring that gives detailed guidance on how such bodies should go about their work. These standards would bolster and embolden the work of bodies with the critical role of protecting human rights. Their role, as the proposed revisions state, is no less than to 'ensure that the conditions of detention and the treatment of prisoners meet the requirements of national and international law, including the provisions of these rules, and that the rights and dignity of prisoners are upheld at all times' (European Committee on Crime Problems 2019b rule 93.1).

As well as revising legal frameworks, particularly through the revision process for the EPRs, European bodies such as the Council of Europe and the European Union should stimulate more research into the actual impact of prison oversight bodies, the barriers they face in their work and the attitudes of staff and prisoners to the process. A vibrant European scholarship on these matters could also be a model for others in trying to ensure their prison systems and their mechanisms for oversight are as good as they can be.

The European approach to imprisonment is often contrasted to the more punitive United States, with authors arguing that its prison law and policy has acted to create a more human rights-oriented approach to imprisonment than that seen in Europe (van Zyl Smit and Snacken 2009). While this may be contested, and the impact in some European countries limited, it is the case that many states in the United States do not have prison oversight bodies (Mushlin and Deitch 2010, Simon 2018), while Council of Europe member states are at least required under the EPRs to set up such bodies. When we also consider that the Council of Europe has created a prison monitoring body of its own, which has developed a set of standards and protocols for monitoring prisons, it is all the more surprising that European prison law has not given more 
prominence to domestic prison inspection and monitoring bodies. It is time to fill this gap, and for Europe to ensure that some of its most hidden places are subject to robust and effective oversight.

Acknowledgements I am very grateful to Dr. Ian Cameron, Hugh Chetwynd, Sophie van der Valk and Dr. Eva Aizpurua for their comments on earlier versions of this paper. I am also indebted to the anonymous reviewers for their very helpful feedback

Funding This project has received funding from the European Research Council (ERC) under the European Union's Horizon 2020 research and innovation programme (grant agreement No 679362).

Open Access This article is distributed under the terms of the Creative Commons Attribution 4.0 International License (http://creativecommons.org/licenses/by/4.0/), which permits unrestricted use, distribution, and reproduction in any medium, provided you give appropriate credit to the original author(s) and the source, provide a link to the Creative Commons license, and indicate if changes were made.

\section{References}

Anagnostaras, G. (2016). Mutual confidence is not blind trust! Fundamental rights protection and the execution of the European arrest warrant: Aranyosi and Căldăraru. Common Market Law Review, 53, 1675.

Bennett, J. (2016). The working lives of prison managers: global change, local culture and individual agency in the late modern prison. London: Palgrave Macmillan.

Bicknell, C., \& Evans, M. (2017). Monitoring prisons: the increasingly complex relationship between international and domestic frameworks. In Daems \& Robert (Eds.), Europe in Prisons (pp. 11-35). London: Palgrave Macmillan.

Carrabine, E. (2004). Criminology: A Sociological Introduction. Abingdon: Routledge.

Committee of Ministers. (2014). Communication from the authorities (information on the implementation of the implementation of the action plan), 1201st meeting (DH), DH-DD(2014)471, April 82014.

Committee of Ministers. (2015). (20 November 2015) Communication from Italy concerning the case of Torregiani and others against Italy (Application No. 43517/09), 1243 meeting (DH), DH-DD(2015)1251.

Committee of Ministers. (2017). Decisions. CM/Del/Dec(2017)1288/H46-24, 1288th meeting, (DH) June 6-7 2017.

Committee of Ministers. (2019). Communication from Hungary concerning the Istvan Gabor Kovacs group of cases and the case of Varga v. Hungary (Applications No. 15707/10, 14097/12), 1348th meeting, DHDD(2019)311, March 212019.

CPT. (1992). 2nd General Report of the CPT.

CPT. (2010a). Report to the Hungarian Government on the visit to Hungary carried out by the CPT from 24 March to 2 April 2009, CPT/Inf (2010) 16.

CPT. (2010b). Report to the Italian Government on the visit to Italy carried out by the CPT from 14 to 26 September 2008. CPT/Inf (2010) 12.

CPT. (2014a). Report to the Lithuanian Government on the visit to Lithuania carried out by the CPT from 27 November to 4 December 2012, CPT/Inf (2014) 18.

CPT. (2014b). Report to the Government of Montenegro on the visit to Montenegro carried out by the CPT from 13 to 20 February 2013, CPT/Inf (2014) 16.

CPT. (2014c). Report to the Croatian Government on the visit to Croatia carried out by the CPT from 19 to 27 September 2012. CPT/Inf (2014) 9.

CPT. (2015a). 25th General Report on the CPT's activities.

CPT. (2015b). Report to the Government of the United Kingdom on the visit to Gibraltar carried out by the CPT from 13 to 17 November 2014. CPT/Inf (2015) 40.

CPT. (2015c). Report to the Czech Government on the visit to the Czech Republic carried out by the CPT from 1 to 10 April 2014, CPT/Inf (2015) 18.

CPT. (2015d). Report to the Government of Ireland on the visit to Ireland carried out by the CPT from 16 to 26 September 2014, CPT/Inf (2015) 38.

CPT. (2015e). Report to the Bulgarian Government on the visit to Bulgaria carried out by the CPT from 24 March to 3 April 2014. CPT/Inf (2015) 12. 
CPT. (2016a). Report to the Government of Serbia on the visit to Serbia carried out by the CPT from 26 May to 5 June 2015. CPT/Inf (2016) 21.

CPT. (2016b). Report to the United Nations Interim Administration Mission in Kosovo (UNMIK) on the visit to Kosovo carried out by the CPT from 15 to 22 April 2015, CPT/Inf (2016) 23.

CPT. (2017a). Report to the Government of 'The Former Yugoslav Republic of Macedonia' on the visit to 'the former Yugoslav Republic of Macedonia' carried out by the CPT from 6 to 9 December 2016. CPT/Inf (2017) 30 .

CPT. (2017b). Report to the Spanish Government on the visit to Spain carried out by the CPT from 27 September to 10 October 2016. CPT/Inf (2017) 34.

CPT. (2017c). Report to the Slovenian Government on the visit to Slovenia carried out by the CPT from 2 March to 4 April 2017. CPT/Inf (2017) 27.

CPT. (2018). Report to the Bulgarian Government on the visit to Bulgaria carried out by the CPT from 25 September to 6 October 2017. CPT/Inf (2018) 15.

Crewe, B. (2009). The Prisoner Society: Power, Adaptation and Social Life in an English Prison. Oxford: Clarendon Press.

Daems, T. (2016). Slaves and states: torture prevention in contemporary Europe. British Journal of Criminology, 57(3), 627-643.

Daems, T., van Zyl Smit, D., \& Snacken, S. (Eds.). (2014). European Penology? London: Hart Publishing.

Daems, T., \& Robert, L. (Eds.). (2017). Europe in Prisons. London: Palgrave Macmillan.

Dünkel, F., \& Morgenstern, C. (2018). The monitoring of prisons in German law and practice. Crime, Law and Social Change, 70(1), 93-112.

European Committee on Crime Problems, Council for Penological Co-operation (2017). Doc. PC-CP 14.

European Committee on Crime Problems, Council for Penological Co-operation. (2018a). Revised Commentary to Recommendation $\mathrm{CM} / \operatorname{Rec}(2006) 2$ of the Committee of Ministers to Member States on the European Prison Rules, (2018) 1 rev 2. https://rm.coe.int/pc-cp-2018-1-e-rev-2-epr-2006-with-changes-andcommentary-22-may-2018/16808add21. Accessed 19 May 2019.

European Committee on Crime Problems, Council for Penological Co-operation. (2018b). Revised Rules and Commentary to Recommendation CM/Rec(2006)2 of the Committee of Ministers to Member States on the European Prison Rules. PC-CP 2018) 15.

European Committee on Crime Problems, Council for Penological Co-operation. (2018c). Revised Rules and Commentary to Recommendation CM/Rec(2006)2 of the Committee of Ministers to Member States on the European Prison Rules. PC-CP (2018) 15 rev 3.

European Committee on Crime Problems, Council for Penological Co-operation. (2018d). Revised Rules and Commentary to Recommendation CM/Rec(2006)2 of the Committee of Ministers to Member States on the European Prison Rules. PC-CP (2018) 15 rev 4.

European Committee on Crime Problems, Council for Penological Co-operation. (2019a). Revised Rules and Commentary to Recommendation CM/Rec(2006)2 of the Committee of Ministers to Member States on the European Prison Rules. PC-CP (2018) 15 rev 5.

European Committee on Crime Problems, Council for Penological Co-operation. (2019b). Revised Rules and Commentary to Recommendation CM/Rec(2006)2 of the Committee of Ministers to Member States on the European Prison Rules. PC-CP (2018) 15 rev 6.

European Council. (2010). OJ C 115, "Information and Notices" 4 April 2010.

European Parliament. (2011). European Parliament Resolution of 15 December 2011 on detention conditions in the EU. 2011/2897(RSP).

European Parliament. (2014). European Parliament resolution of 27 February 2014 with recommendations to the Commission on the review of the European Arrest Warrant. 2013/2109 INL (2014).

Evans, M., \& Morgan, R. (1998). Preventing torture: a study of the European convention for the prevention of torture and inhuman or degrading treatment or punishment. Oxford: Clarendon.

Favuzza, F. (2017). Torreggiani and Prison Overcrowding in Italy. Human Rights Law Review, 17(1), $153-173$.

Glas, L. R., \& Krommendijk, J. (2017). From Opinion 2/13 to Avotinšs: recent developments in the relationship between the Luxembourg and Strasbourg Courts. Human Rights Law Review, 17(3), 567-587.

Hardwick, N., \& Murray, R. (2019). Regularity of OPCAT visits by NPMs in Europe. Australian Journal of Human Rights. https://doi.org/10.1080/1323238X.2019.1588054.

Lappi-Seppäla, T., \& Koskenniemi, L. (2018). National and regional instruments in securing the rule of law and human rights in the Nordic prisons. Crime, Law and Social Change, 70(3), 135-159.

Liebling, A., \& Arnold, H. (2004). Prisons and their moral performance: a study of values, quality, and prison life. Oxford: Clarendon.

Liebling, A., \& Crewe, B. (2013). Prisons beyond the new penology: the shifting moral foundations of prison management. In Simon \& Sparks (Eds.), The SAGE handbook of punishment and society (pp. 283-301). London: Sage. 
Liebling, A., \& Maruna, S. (Eds.). (2006). The Effects of Imprisonment. Abingdon: Routledge.

Morgan, R., \& Evans, M. (1994). Inspecting prisons - the view from Strasbourg. British Journal of Criminology, $34,141$.

Morgan, R., \& Evans, M. (1999). Protecting prisoners: the standards of the European Committee for the Prevention of Torture in context. Oxford: Oxford University Press.

Murray, R.S., E., Evans, M., Hallo de Wolf, A. (2011). The Optional Protocol to the UN Convention Against Torture. Oxford: Oxford University Press.

Mushlin, M., \& Deitch, M. (2010). Opening up a closed world: what constitutes effective prison oversight? Pace Law Review, 30, 1383-1406.

Padfield, N. (2018). Monitoring prisons in England and Wales: who ensures the fair treatment of prisoners? Crime, Law and Social Change, 70(1), 57-76.

Rodley, N. (2015). Standards brought up to standard. Blogpost for Penal Reform International, available at: https://www.penalreform.org/blog/standards-brought-up-to-standard/. Accessed 9 July 2019.

Simon, J. (2017). The second coming of dignity. In Dolovich \& Natapoff (Eds.), Mapping the new criminal justice thinking (p. 275). New York: NYU Press Scholarship.

Simon, J. (2018). Penal monitoring in the United States: lessons from the American experience and prospects for change. Crime, Law and Social Change, 70(1), 161-173.

Snacken, S. (2010). Resisting Punitiveness in Europe? Theoretical Criminology, 14(3), 273-292.

Snacken, S., \& Dumortier, E. (Eds.). (2012). Resisting punitiveness in Europe?: welfare, human rights and democracy. Abingdon: Routledge.

Tankebe, \& Liebling (Eds.). (2013). Legitimacy and Criminal Justice: An International Exploration. Oxford: Oxford University Press.

United Nations Office on Drugs and Crime. (2017). Assessing compliance with the Nelson Mandela rules: a checklist for internal inspection mechanisms. New York: UNODC.

Vagg, J. (1994). Prison systems: a comparative study of accountability in England, France, Germany, and the Netherlands. Oxford: Oxford University Press.

van Zyl Smit, D. (2010). Regulation of prison conditions. Crime and Justice, 39, 503-563.

van Zyl Smit, D., \& Snacken, S. (2009). Principles of European prison law and policy: penology and human rights. Oxford: Oxford University Press.

van Zyl Smit, D., Weatherby, P., \& Creighton, S. (2014). Whole life sentences and the tide of European human rights jurisprudence: what is to be done? Human Rights Law Review, 14(1), 59-84.

Xanthopoulou, E. (2018). Mutual trust and rights in EU criminal and asylum law: three phases of evolution and the uncharted territory beyond blind trust. Common Market Law Review, 55(2), 489-509.

Publisher's Note Springer Nature remains neutral with regard to jurisdictional claims in published maps and institutional affiliations. 